\title{
Comparison of nasal geometry among adults with obstructive sleep apnea: a preliminary study
}

\author{
Jackson Ítalo Tavares da Rocha ${ }^{1}$ \\ https://orcid.org/0000-0002-5852-4486 \\ Anna Myrna Jaguaribe de Lima² \\ https://orcid.org/0000-0002-4224-4009 \\ Hilton Justino da Silva ${ }^{1}$ \\ https://orcid.org/0000-0002-6852-3233 \\ Adriana de Oliveira Camargo Gomes ${ }^{1}$ \\ https://orcid.org/0000-0002-1871-9502 \\ Paulo Augusto Vitorino ${ }^{1}$ \\ https://orcid.org/0000-0001-5362-4157 \\ Danielle Cristina Silva Clímaco ${ }^{3}$ \\ https://orcid.org/0000-0003-1935-1540 \\ Daniele Andrade da Cunha ${ }^{1}$ \\ https://orcid.org/0000-0002-3987-9740
}

Universidade Federal de Pernambuco, Centro de Ciências da Saúde, Programa de Pós-Graduação (Mestrado) em Saúde da Comunicação Humana, Recife, Pernambuco, Brasil.

2 Universidade Federal Rural de Pernambuco, Recife Pernambuco, Brasil. ${ }^{3}$ Hospital Otávio de Freitas, Ambulatório de Pneumologia, Recife, Pernambuco, Brasil.

This work was carried out at the Department of Speech Therapy of the Center for Health Sciences, Universidade Federal de Pernambuco - UFPE, Recife, Pernambuco, Brazil.

Research support sources: Universal Edital /CNPQ/Universal 14/2014 - Process 457261/2014-5-APQ; Coordenação de Aperfeiçoamento de Pessoal de Nível Superior (CAPES)

Conflict of interests: Nonexistent

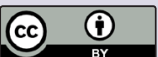

Received on: July 5, 2019

Accept on: November 13, 2019

Corresponding addres:

Adriana de Oliveira Camargo Gomes

Departamento de Fonoaudiologia - UFPE

Rua Professor Artur de Sá, s/n. Cidade

Universitária

CEP: 50740-520 - Recife, Pernambuco,

Brasil

E-mail: acamargogomes@gmail.com

\section{ABSTRACT}

Purpose: to compare nasal geometry between two groups of patients with different degrees of obstructive sleep apnea and to correlate apnea-hypopnea index, apnea severity and degree of daytime sleepiness with nasal areas and volume.

Methods: a total of 20 adults ( 15 women and 5 men, mean age of $52.0 \pm 11.4$ years old) without nasal obstruction were submitted to polysomnography. The subjects were divided into two groups: a) 10 individuals without apnea or with mild-grade apnea; b) 10 with moderate or severe apnea. Nasal geometry was evaluated by acoustic rhinometry. The volume, comprising the distance from the nasal valve to the posterior part of the middle nasal turbinate, and the three sectional areas corresponding to nasal valve, anterior part of the inferior nasal turbinate and posterior part of the inferior nasal turbinate, were considered. The Shapiro-Wilk, Mann-Whitney, Student's t tests for independent samples and Spearman's correlation coefficient were used for the analysis, with a significance level lower than $5 \%$.

Results: group 2 presented lower values in the area corresponding to the nasal valve (on the right), and higher values in the nasal turbinate areas. There was no correlation between the drowsiness scale and nasal areas and volumes.

Conclusion: the area of the nasal valve was unilaterally smaller in the group with moderate and severe apnea. There was no correlation between volumes and nasal areas and excessive daytime sleepiness.

Keywords: Obstructive Sleep Apnea; Acoustic Rhinometry; Diagnosis; Nasal Obstruction; Nasal Cavity 


\section{INTRODUCTION}

Obstructive sleep apnea (OSA) is a chronic, developmental disorder characterized by respiratory dysfunction during the sleep period, secondary to anatomic-structural and neuromuscular factors. The main symptoms are: daytime hypersomnia, frequent awakening, snoring, airflow interruptions, restless sleep, neurocognitive deficits, headache, cardiovascular problems, and behavioral changes ${ }^{1-5}$.

It is known that the etiology of OSA is multifactorial and that morphometric and functional changes in oropharyngeal and nasal structures are among the cause and effect processes of OSA ${ }^{6,7}$. These changes promote upper airways (UAW) narrowing, one of the main factors for the emergence of this disorder ${ }^{6-8}$.

Although the influence of nasal obstruction on OSA $^{9}$ has not been proven, one study indicated a high incidence of nasal structural alterations in patients with this sleep disorder ${ }^{10}$, which justifies further research on the subject.

The gold-standard method for OSA diagnosis is polysomnography ${ }^{11}$. However, other screening procedures may be useful for combining different risk factors ${ }^{12}$, such as airway abnormalities, including examinations that assess nasal cavity geometry ${ }^{8,13}$.

Acoustic rhinometry (AR) is characterized by a procedure to measure nasal geometry, which means the volumes, areas and distances of the nasal cavity cross-sections, enabling identification of possible obstructions $^{8,13}$. In this context, AR can to identify risk factors for developing and aggravating OSA related to nasal cavity obstructions, and may be adopted as an auxiliary method in order to detect anatomical changes which accompany the onset and evolution of the disease $^{8,13}$.

Thus, the use of AR may be an important ally in the complementary diagnosis of obstructive sleep apnea (OSA), since anatomical alterations of the airways are associated with this disease ${ }^{14-16}$.

Therefore, in order to verify the association of nasal measurements with obstructive sleep apnea, the objective of this study was to compare the rhinometric measurements of sectional areas and nasal volumes between two groups with different degrees of apnea, namely, individuals without OSA or with mild-grade
OSA, and individuals with moderate or severe OSA undergoing polysomnography for diagnosis, and then, correlating apnea and hypopnea index, apnea severity, and degree of daytime sleepiness with nasal areas and volume.

\section{METHODS}

This is a primary, observational, cross-sectional, descriptive-analytic, quantitative study conducted at the Orofacial Motricity Laboratory of the Universidade Federal de Pernambuco and at the Pneumology outpatient clinic of Otávio de Freitas Hospital.

The study was approved under opinion no. 865,491 by the Human Research Ethics Committee of the Health Sciences Center of the Universidade Federal de Pernambuco, Brazil. All the subjects signed the free and informed consent form before data collection was initiated.

Adults of both genders, aged above 18 years, without complaint of nasal obstruction or previous nasal surgeries, submitted to polysomnography (PSG) attended at the Ambulatory of Pulmonology for OSA diagnosis, between January 2013 and December 2015 were recruited. Patients who presented other sleep disorders, who were potentially using sedatives or chemical dependents, who showed craniofacial and upper airway anatomical changes, and those in therapy using spiromics devices or CPAP were excluded from the study.

All the patients attended the service for apnea complaints, and therefore were submitted to polysomnography for diagnosis. The recruited subjects had already undergone medical evaluation, in which nasal anatomical changes that could influence the examination result were ruled out. The inclusion and exclusion criteria were applied according to the medical examination results.

Thus, 20 patients ( 15 women and 5 men) were analyzed, with a mean age of $52.0 \pm 11.4$ years and $\mathrm{BMI}=31.9 \pm 9.0 \mathrm{~kg} / \mathrm{m}^{2}$, with no complaint of nasal obstruction. After polysomnographic analysis, subjects were divided into two groups: a) group 1 - individuals without OSA and patients with mild-grade OSA; b) group 2 - patients with moderate or severe OSA (Figure 1). 


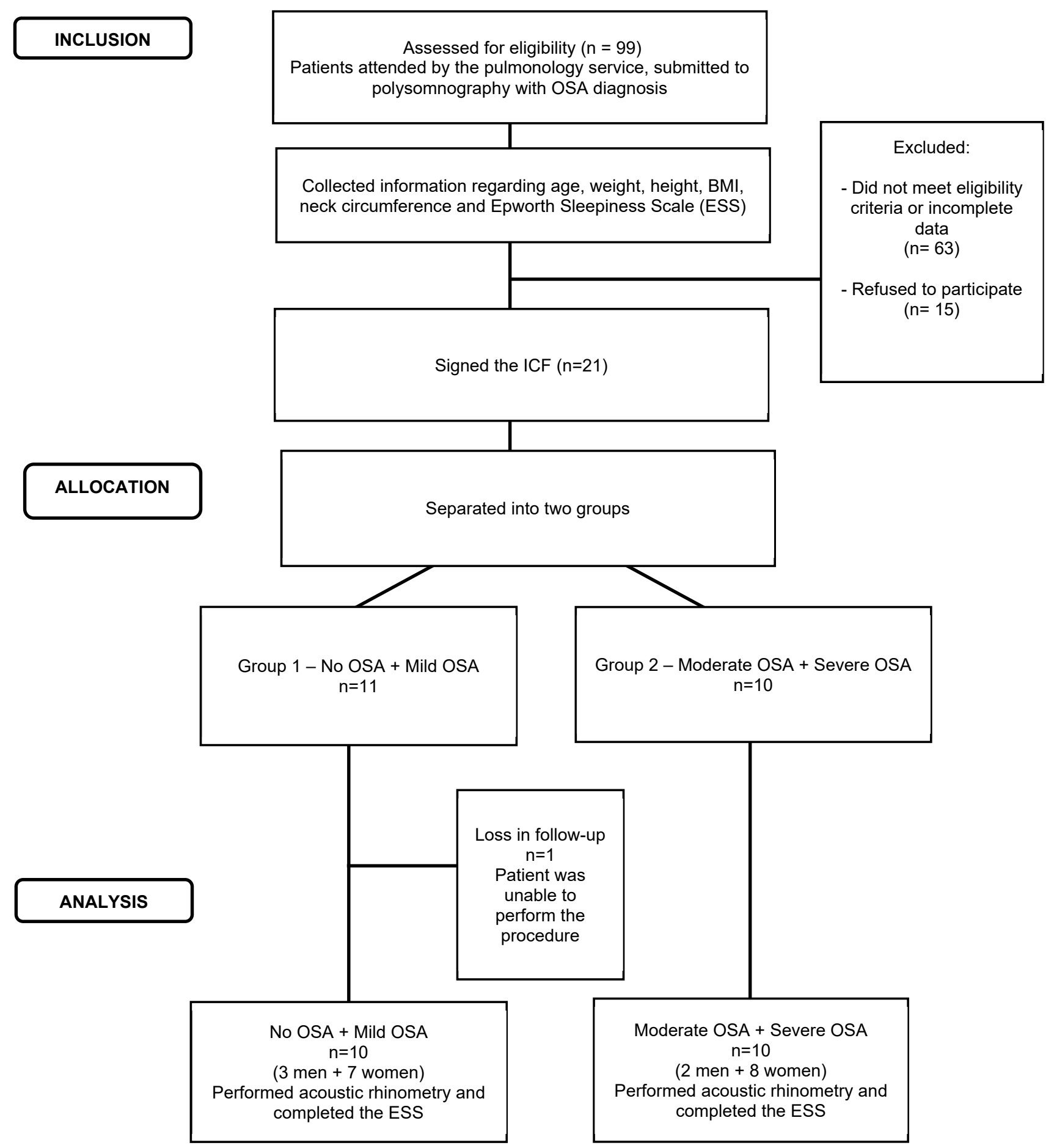

Legends: OSA - obstructive sleep apnea; ESS - Epworth Sleepiness Scale; ICF - Informed Consent Form; BMI - body mass index; $\mathrm{n}$ - number of subjects

Figure 1. Flowchart of the research data collection procedure

The anthropometric evaluation consisted of a weight and height measurement performed on a digital scale (Welmy, with a capacity of $200 \mathrm{~kg}$, divisions of 100 g) with a stadiometer; the weight was measured in kilograms $(\mathrm{kg})$ and the height in meters $(\mathrm{m})$. Data on body weight and height were used to calculate BMI (Weight $(\mathrm{kg}) /$ Height $\left.^{2}(\mathrm{~m})\right)$. A flexible tape measure with a capacity of up to $150 \mathrm{~cm}$ and increments of $1 \mathrm{~mm}$ was used at the level of the thyroid cartilage to evaluate neck circumference, with the individual in standing posture and anatomical position.

The Epworth Sleepiness Scale (ESE) ${ }^{17,18}$ was applied to quantify the daytime sleepiness degree of the individual. The scale is composed of simple 
questions on the presence of sleep in some daily situations. A score of up to 10 is considered within normal, and above 10 as excessive drowsiness ${ }^{17}$.

The PSG examination was conducted over a complete night on the Hospital's premises, during spontaneous sleep and without any sedation. Monitoring and follow-up of the examination were performed by trained professionals, and a portable respiratory monitor (ApneaLink ${ }^{\top M}$ ) was applied. The device remained switched on between bedtime and when the patient woke up in the morning.

The ApneaLink ${ }^{\mathrm{TM}}$ monitor is able to continuously monitor pulse oximetry, detect respiratory effort (via chest-abdominal tape applied to the patient's body), measure airflow (through a pressure sensor in the nasal pressure cannula, also applied to the patient's face), record snoring and locate body position. In addition, the heart rate is continuously measured by reading the pulse wave by oximetry. All the data are recorded in the device software, and then recorded in the ambulatory itself, according to international standards.

During data analysis from the examination, detection of respiratory events (apnea or hypopnea) were performed by a specialized physician responsible for the diagnostic opinion. As previously described, the presence of apnea was characterized with a reduction of more than $90 \%$ in the baseline airflow, while the presence of an airflow reduction greater than $30 \%$ of the baseline associated with a decrease in $\mathrm{O}_{2}$ saturation $\geq 4 \%$ characterized hypopnea. After analyzing the entire sleep period at night, the sum of all the presented events resulted in the apnea and hypopnea index (AHI), whose value when equal to or greater than 5 events/ hour was the reference for the OSA diagnosis ${ }^{12}$.

In order to perform the nasal cavity geometry evaluation procedure, acoustic rhinometry (AR) was implemented by the Eccovision Acoustic Rhinometer (Sleep Group Solution, North Miami Beach, Florida, USA). The AR enables measuring areas and volume of the nasal cavities, as well as the distance of the different constrictions from the nostrils.

The two nasal cavities were evaluated separately by volume (V) values measured in $\mathrm{cm}^{3}$, which comprised the nasal cavity volume from the nasal valve to the posterior part of the middle nasal turbinate, comprising a distance of $10 \mathrm{~mm}$ to $64 \mathrm{~mm}$, as well as the crosssectional area (CSA) values measured in $\mathrm{cm}^{2}$, with these being: $\mathrm{CSA} 1=$ corresponding to the nasal valve; $\mathrm{CSA} 2$ = corresponding to the anterior part of the lower nasal turbinate; and CSA $3=$ corresponding to the posterior part of the inferior nasal turbinate or average ${ }^{19-21}$. The values obtained in each nostril were also summed so that the volumes and CSA values of the nasal cavities could be analyzed together.

The cross-sectional areas are calculated by the intensity of the reflected wave and captured by the microphone. The distances to the nostril are calculated based on the speed of the reflected sound wave and the time captured by the microphone. The data is converted and displayed in an area-distance function graph represented on the computer screen, called the rhinogram, and the system calculates the values for the volumes by the graph area from these values ${ }^{19,20}$.

Care was taken in relation to the ambient temperature, external noises, rhinotube tube placement during examinations and sealing between the nasal adapter and the nasal cavity to ensure the accuracy of the rhinometric measurements, as described in other studies ${ }^{19,20}$.

Therefore, the ambient temperature was controlled and maintained at approximately $25{ }^{\circ} \mathrm{C}$. After the patient was placed in the examination room for about 30 minutes, individual calibration of the instrument was performed at the beginning of the procedure, and care was taken regarding the correct positioning of the rhinometer tube in order to avoid recording losses of the patients' sound waves. The participant was instructed to sit in an upright position, with their feet well placed in contact with the ground, in addition to keeping their head always stable. At the examination time, the patient was always asked to keep their eyes fixed at a point ahead at eye level in order to maintain the head position.

In order to certify the reproducibility of the examination ${ }^{21}$, the rhinometric measurements were performed by two examiners, and the measurements of each nostril were repeated twice by each of the examiners to confirm the measured values, which could not to defer more than $10 \%$ between them, and to prevent analysis errors due to problems in the collection procedure. The values considered in the result correspond to the second measure obtained by the second evaluator.

The patient was instructed to inhale and exhale three times through their mouth, and the third breath should be held for a few seconds while beeping indicated that measurements were being taken.

The data adherence to normality by the Shapiro-Wilk test was initially tested to analyze the results. The variables which presented normal distribution had their results expressed by mean ( \pm standard deviation), and those which did not present adherence were shown in 
median (minimum-maximum value). The Mann-Whitney test (comparing variables whose values did not present normal distribution) and the Student's $t$ test for independent samples (in the comparison between variables whose values had normal distribution) were used to compare the groups, while the Spearman correlation coefficient was used to test the correlation between the variables. The significance level assumed was lower than $5 \%$ in all situations. The SPSS version 17.0 program was used.

\section{RESULTS}

The values of the variables which characterize the sample were stratified by groups 1 (no OSA and mild OSA) and 2 (moderate and severe OSA). It was observed that the groups only differed in height and (as expected) in apnea and hypopnea index (AHI), which was higher in group 2 (Table 1).

Table 1. Characterization of the sample stratified by the groups $(n=20)$

\begin{tabular}{|c|c|c|c|}
\hline Variables & $\begin{array}{c}\text { GROUP } 1 \\
n=10\end{array}$ & $\begin{array}{c}\text { GROUP } 2 \\
n=10\end{array}$ & $p$ value \\
\hline Age (years) - Mean ( $\pm S D)$ & $49.90( \pm 9.48)$ & $54.1( \pm 13.17)$ & 0.151 \\
\hline Weight $(\mathrm{kg})$ - Mean ( $\pm \mathrm{SD})$ & $72.20( \pm 9.32)$ & $85.87( \pm 18.95)$ & 0.073 \\
\hline Height (m) - Mean ( \pm SD) & $1.62( \pm 0.13)$ & $1.61( \pm 0.08)$ & $0.034^{*}$ \\
\hline BMI $\left(k g / m^{2}\right)$ - Mean $( \pm S D)$ & $30.07( \pm 8.22)$ & $33.81( \pm 9.84)$ & 0.778 \\
\hline Neck circumference $(\mathrm{cm})$ - Mean $( \pm S D)$ & $37.10( \pm 3.90)$ & $40.50( \pm 5.84)$ & 0.651 \\
\hline ESS (score) - Mean ( \pm SD) & $10.50( \pm 6.55)$ & $16.00( \pm 7.30)$ & 0.915 \\
\hline AHI (events/h) - Median (Min-Max) & $5.20(2.0-11.30)$ & $36.40(15.3-94.40)$ & 0.000 ** \\
\hline
\end{tabular}

* Student's $t$ test for independent samples - level of significance $p<0.05$

** Mann-Whitney Test - level of significance $p<0.05$

Legend: Group 1 - No OSA/Mild OSA; Group 2 -Moderate OSA/Severe OSA; AHI - Apnea and Hypopnea Index; BMI - Body Mass Index; ESS - Epworth Sleepiness Scale; SD - Standard deviation; Min-Max - minimum and maximum values.

The mean values found in AR for the CSA and of the nasal cavity volumes (V) of both groups were calculated (Table 2). When comparing the left and right nasal cavities separately, it was observed that group 2 presented a lower value in CSA1 (corresponding to the nasal valve) in the right nasal cavity compared to group 1 , and a higher value in the left CSA2 and total CSA3, meaning in the analysis of the sum of the two cavities.

Thus, there was a difference between the groups regarding the values of three variables in the sectional areas, but there was no difference in six area variables or in volumes.
The mean values calculated by gender did not differ, except between the left CSA1 measurements ( $p=$ 0.013 ), in which the male group had an average value of $1.04 \mathrm{~cm}^{2}$ and the female group presented $0.67 \mathrm{~cm}^{2}$.

Regarding the correlation test results between the variables related to OSA and nasal measurements, the values indicate that there was a positive correlation between the $\mathrm{AHI}$ and the severity of OSA and total CSA3. However, there was no correlation between the Epworth sleepiness scale and the rhinometric variables (Table 3). 
Table 2. Values of areas and volumes assessed by acoustic rhinometry stratified by gender and by group

\begin{tabular}{|c|c|c|c|c|c|c|}
\hline Variables & $\underset{n=5}{M}$ & $\begin{array}{c}F \\
n=10\end{array}$ & $\mathbf{p}$ & $\begin{array}{c}\text { GROUP } 1 \\
n=10\end{array}$ & $\begin{array}{c}\text { GROUP } 2 \\
n=10\end{array}$ & $p$ value \\
\hline CSA1 D (cm²) - Mean ( \pm SD) & $1.15( \pm 0.27)$ & $0.75( \pm 0.24)$ & 0.926 & $0.94( \pm 0.36)$ & $0.77( \pm 0.20)$ & 0.045 * \\
\hline CSA1 E $\left(\mathrm{cm}^{2}\right)$ - Median (Min-Max) & $1.04( \pm 0.43)$ & $0.67( \pm 0.18)$ & $0.013^{*}$ & $0.70(0.41-1.26)$ & $0.72(0.35-1.70)$ & 0.821 \\
\hline CSA1 total $\left(\mathrm{cm}^{2}\right)$ - Mean $( \pm S D)$ & $2.20( \pm 0.51)$ & $1.42( \pm 0.37)$ & 0.262 & $1.67( \pm 0.61)$ & $1.56( \pm 0.45)$ & 0.152 \\
\hline CSA2 R $\left(\mathrm{cm}^{2}\right)$ - Mean $( \pm \mathrm{SD})$ & $3.01( \pm 1.02)$ & $2.02( \pm 1.09)$ & 0.954 & $1.99( \pm 0.97)$ & $2.55( \pm 1.26)$ & 0.333 \\
\hline CSA2 L (cm²) - Mean ( \pm SD) & $3.08( \pm 1.01)$ & $2.07( \pm 0.91)$ & 0.759 & $1.93( \pm 0.61)$ & $2.71( \pm 1.21)$ & 0.035 * \\
\hline CSA2 total $\left(\mathrm{cm}^{2}\right)-$ Mean $( \pm S D)$ & $6.09( \pm 1.74)$ & $4.09( \pm 1.84)$ & 0.802 & $3.92( \pm 1.51)$ & $5.26( \pm 2.23)$ & 0.172 \\
\hline CSA3 R $\left(\mathrm{cm}^{2}\right)$ - Median (Min-Max) & $3.66( \pm 2.01)$ & $3.01( \pm 1.92)$ & 0.822 & $2.27(1.27-5.89)$ & $3.20(1.16-7.20)$ & 0.290 \\
\hline CSA3 L (cm²) - Median (Min-Max) & $4.21( \pm 2.53)$ & $2.98( \pm 1.66)$ & 0.338 & $2.44(1.67-4.16)$ & $3.58(0.47-8.10)$ & 0.212 \\
\hline CSA3 total $\left(\mathrm{cm}^{2}\right)$ - Mean $( \pm S D)$ & $7.87( \pm 4.27)$ & $5.99( \pm 3.40)$ & 0.467 & $5.21( \pm 2.23)$ & $7.71( \pm 4.37)$ & 0.025 * \\
\hline V R $\left(\mathrm{cm}^{3}\right)$ - Mean $( \pm \mathrm{SD})$ & $14.54( \pm 4.14)$ & $9.81( \pm 3.81)$ & 0.779 & $10.55( \pm 4.22)$ & $11.43( \pm 4.62)$ & 0.502 \\
\hline $\mathrm{VL}\left(\mathrm{cm}^{3}\right)$ - Mean $( \pm \mathrm{SD})$ & $14.88( \pm 3.78)$ & $9.99( \pm 3.55)$ & 0.894 & $10.58( \pm 3.44)$ & $11.84( \pm 4.81)$ & 0.337 \\
\hline$V$ total $\left(\mathrm{cm}^{3}\right)$ - Mean $( \pm \mathrm{SD})$ & $29.42( \pm 6.62)$ & $19.79( \pm 6.71)$ & 0.770 & $21.126( \pm 7.22)$ & $23.27( \pm 8.57)$ & 0.370 \\
\hline
\end{tabular}

* Student's $t$ test for independent samples - level of significance $p<0.05$

** Mann-Whitney Test - level of significance $\mathrm{p}<0.05$

Legend: M - male; F - female; Group 1 - No OSA/Mild OSA; Group 2 -Moderate OSA/Severe OSA; CSA - Cross-sectional Area; V - Volume, corresponding to the distance of $10 \mathrm{~mm}$ to $64 \mathrm{~mm}$ from the nostril; R - Right nasal cavity; L - Left nasal cavity; SD - standard deviation; Min-Max - minimum and maximum values

Table 3. Correlation between the Apnea and Hypopnea Index, OSA severity and Epworth Sleepiness Scale variables with total areas and volume

\begin{tabular}{cccccc}
\hline Variables & Correlation & CSA1 Total & CSA2 Total & CSA3 Total & Total Volume \\
\hline \multirow{2}{*}{ AHI (events/h) } & rho & 0.042 & 0.370 & 0.475 & 0.297 \\
& p value & 0.860 & 0.108 & $\mathbf{0 . 0 3 4}$ & 0.203 \\
ESS & rho & -0.064 & -0.054 & -0.046 & -0.115 \\
& p value & 0.788 & 0.820 & 0.847 & 0.628 \\
Severity of OSA & rho & 0.023 & 0.389 & 0.459 & 0.280 \\
& p value & 0.922 & 0.090 & $\mathbf{0 . 0 4 2}$ * & 0.231 \\
\hline
\end{tabular}

*Spearman's correlation coefficient test - level of significance $p<0.05$

Legend: AHI - Apnea and Hypopnea Index; CSA - Cross-sectional Area; ESS - Epworth Sleepiness Scale; rho - Spearman's correlation coefficient

\section{DISCUSSION}

The structural alterations of the nasal cavity have been related to the presence of OSA, but there is still some clarification regarding its association with the etiology of this disease ${ }^{10,22,23}$, despite the relationship between nasal obstruction and morphological alterations which generate diseases such as mouth-breathing substitution, snoring, and consequently $\mathrm{OSA}^{10}$.

The present investigation aimed to verify factors which could be predictive of OSA in a group without nasal complaints by evaluating nasal geometry measurements, comparing one group without OSA or having mild-degree OSA with another group diagnosed with moderate or severe OSA in order to illustrate the possible relationship of nasal morphology with the presence and degree of OSA.

Regarding the studied sample, it can be noted that the two groups were composed mostly of women: $70 \%$ in group 1 and $80 \%$ in group 2 (Figure 1). When testing the difference of all the measures evaluated between the genders, and despite the fact that the male sample was much smaller, there was no significance except between the left CSA1 measurements $(p=0.013)$, in which the male group had a higher average value than the female group $\left(1.04 \mathrm{~cm}^{2}\right.$ vs. $0.67 \mathrm{~cm}^{2}$, respectively). 
Considering that men and women did not differ in the total area and volume measurements, it was decided to not exclude men from the sample.

It is worth noting that the two studied groups did not differ in age and body measurements, except for the height measure which was lower in the group with moderate and severe OSA (Table 1). This presupposes a certain homogeneity between the groups, which favors the analysis regarding the isolation of the variables to be analyzed, i.e. nasal geometry and OSA degree. The groups differed in relation to $\mathrm{AHI}$, as was already clearly predicted, as it was the factor used to stratify the groups. It should also be noted that there was no difference between the mean ESE scores, which does not corroborate the literature ${ }^{17}$.

AR is pointed as an objective examination of the nasal cavity, highlighting its usefulness in clinical

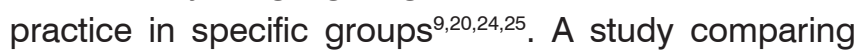
the means of CSA1 and CSA2 of 108 individuals with and without OSA found a difference of $10-22 \%$ in CSA1 and CSA2 between groups ${ }^{26}$. These findings partially corroborate the present study; it is noted that group 2 presented lower values in the right CSA1 in relation to group 1, however group 2 presented higher values in left CSA2, as well as total CSA3 (Table 2).

This result seems to contradict the initial hypothesis at first, since the measures corresponding to the nasal turbinate region (CSA2 and CSA3) ${ }^{19-21}$ were higher in the group with moderate and severe OSA. However, considering that CSA1 corresponds to the nasal valve area $^{21}$ and that it offers greater resistance to airflow, a smaller CSA1 area in group 2 points to possible interference of this measure in $\mathrm{OSA}^{27}$, although the later areas have larger dimensions.

Moreover, it is important to note that the group of patients evaluated in the aforementioned study consisted of almost $70 \%$ of individuals with severe $\mathrm{OSA}^{8}$, which may also explain the difference in results in relation to the present study which refer to CSA2.

In another study ${ }^{27}$, AR findings in 87 individuals who presented OSA complaints and signs prior to PSG diagnosis also showed lower values for the minimum CSA, characterizing larger nasal obstructions, corroborating the results obtained in this study in which the CSA1 for all the studied subjects corresponded to the smaller cross-sectional area, thus corresponding to the minimum CSA.

A positive correlation was found between CSA3 measurements with $\mathrm{AHI}$ and the OSA severity in the present sample (Table 3). However, these findings are in agreement with the hypothesis that nasal obstruction can be considered in the OSA etiology, considering that being positive indicates that the larger the area, the greater the AHI and the OSA severity found. Therefore, the idea that the nasal valve had a greater influence on the OSA in this group without nasal complaints than the posterior areas and the volume.

No correlation was found between the total areas of the first two segments of the nasal cavity or the total volume with $\mathrm{AHI}$ and the apnea severity (Table $3)$, thus corroborating other studies ${ }^{16,23}$. One possible justification for the finding is that nasal resistance is an important factor for the onset of the disease, which is not evaluated by $\mathrm{AR}^{23}$.

Likewise, no correlation was observed when analyzing the nasal cavity geometry and the daytime sleepiness level (the main symptom of OSA), which is different from another study which despite indicating an evaluation of daytime hypersomnia, does not mention whether the patients had an OSA diagnosis or its degree ${ }^{28}$. Another important factor to be analyzed is that the population of this study had a nasal obstruction complaint, which also differs from the present study.

Excessive daytime sleepiness (EDS), which is obtained subjectively through the Epworth Sleepiness Scale (ESS) score, can be defined as the inability to stay awake and alert during the day ${ }^{18}$. This inability may be due to sleep disorders in general and not exclusively to obstructive sleep apnea (OSA). Both groups in the present study presented EDS (ESS > 10), and there was no difference between them. The diagnosis through polysomnography in our sample was specifically done for OSA, and the presence of other sleep disorders which could also be responsible for the presence of EDS were not verified.

It should be emphasized that the subjects of the present study did not present any complaint or evidence of nasal obstruction, which may explain the absence of correlation between the majority of the rhinometric variables and the apnea indicators. This can be explained by the pathophysiology of OSA, in which the UAW collapse in turn causes respiratory obstruction, which arises from a series of factors, more specifically a reduction in soft tissue motility during the respiratory cycle, with the tongue, pharyngeal walls and the soft palate structures being essential in this process $^{29}$. Therefore, rhinometry enables us to observe obstructions in the nasal cavity, which are not always present in all individuals with OSA. 
However, considering the difference found in this sample without nasal complaints and with this being a preliminary study, a study with a sample involving a greater number of subjects and stratifying them into individuals without apnea and into the three different degrees of OSA is necessary in order to confirm the importance of acoustic rhinometry as a complementary instrument for evaluating individuals with signs or symptoms of apnea.

Therefore, longitudinal studies evaluating the nasal geometry of these patients starting from diagnosis to treatment for OSA are suggested in order to verify the influence of the most diverse procedures used to treat the pathology of the nasal structures.

\section{CONCLUSION}

As determined from the measured rhinometric measurements, the sectional area corresponding to the nasal valve was unilaterally lower in the group with moderate and severe apnea, in relation to the individuals without OSA or mild OSA. However, no correlation was observed between the volumes and nasal areas and excessive daytime sleepiness, one of the main symptoms directly related to obstructive sleep apnea in the group studied.

\section{REFERENCES}

1. Figueiredo AC, Lorenzi MC, Prezzoti S, Cabral MM, Sennes LU, Lorenzi-Filho G. Efeitos da pressão positiva contínua em vias aéreas sobre os sintomas nasofaríngeos em pacientes com a síndrome da apneia obstrutiva do sono. J Bras Pneumol. 2004;30(6):535-9.

2. Jordan AS, Mcsharry DG, Malhotra A. Adult obstructive sleep apnea. The Lancet. 2014;383(9918):736-47.

3. Osman AM, Carter SG, Carberry JC, Eckert DJ. Obstructive sleep apnea: current perspectives. Nat Sci Sleep. 2018;3(10):21-34. doi: 10.2147/NSS. S124657. eCollection 2018.

4. Miller JD, Aronis KN, Chrispin J, Patil KD, Marine $\mathrm{JE}$, Martin SS et al. Obesity, exercise, obstructive sleep apnea, and modifiable atherosclerotic cardiovascular disease risk factors in atrial fibrillation. J Am Coll Cardiol. 2015;66(25):2899-906.

5. Marcus CL, Moore RH, Rosen CL, Giordani B, Garetz SL, Taylor HG et al. A randomized trial of adenotonsillectomy for childhood sleep apnea. Engl J Med. 2013;368(25):2366-76.
6. Daves RJO, Stradling JR. The efficacy of nasal continuous positive airway pressure in the treatment of obstructive sleep apnea syndrome is proven. Am J Respir Crit Care Med. 2000;161(6):1775-6.

7. Guimarães KCC, Drager LF, Genta PR, Marcondes $B F$, Lorenzi-Filho $G$. Effects of oropharyngeal exercises on patients with moderate obstructive sleep apnea syndrome. Am J Respir Crit Care Med. 2009;179(10):962-6.

8. Banabilh SM, Suzina AH, Mohamad H, Dinsuhaimi S, Samsudin AR, Singh GD. Assessment of 3-D nasal airway morphology in Southeast Asian adults with obstructive sleep apnea using acoustic rhinometry. Clin Oral Investig. 2010;14(5):491-8. doi: 10.1007/s00784-009-0342-9.

9. Migueis DP, Thuler LCS, Lemes LNA, Moreira CSS, Joffily L, Araújo-Melo MHA. Systematic review: the influence of nasal obstruction on sleep apnea. Braz J Otorhinolaryngol. 2016;82(2):223-31.

10. Mekhitarian NL, Fava AS, Lopes HC, Stamm A. Estudo epidemiológico das alterações estruturais da cavidade nasal associadas à síndrome da apnéia e hipopnéia obstrutiva do sono (SAHOS). Rev. Bras. Otorrinolaringol. 2005;71(4):464-6.

11. Bosi M, De Vito A, Kotecha B, Viglietta L, Braghiroli $A$, Steier $\mathrm{J}$ et al. Phenotyping the pathophysiology of obstructive sleep apnea using polygraphy/ polysomnography: a review of the literature. Sleep Breath. 2018;22(3):579-92. doi: 10.1007/ s11325-017-1613-3.

12. Vaz AP, Drummond $M$, Caetano Mota $P$, Severo M, Almeida J, Carlos Winck J. Tradução do Questionário de Berlim para língua Portuguesa e sua aplicação na identificação da SAOS numa consulta de patologia respiratória do sono. Rev Port Pneumol. 2011;17(2):59-65.

13. Moxness MH, Bugten V, Thorstensen WM, Nordgård S, Bruskeland G. A comparison of minimal cross sectional areas, nasal volumes and peak nasal inspiratory flow between patients with obstructive sleep apnea and healthy controls. Rhinology. 2016;54(4):342-7. doi: 10.4193/ Rhin16.085.

14. Awad Ml, Kacker A. Nasal obstruction considerations in sleep apnea. Otolaryngol Clin North Am. 2018;51(5):1003-9.doi: 10.1016/j. otc.2018.05.012.

15. Fu D, Pinto JM, Wang L, Chen G, Zhan X, Wei Y. The effect of nasal structure on olfactory function in 
patients with OSA. Euro Arch Oto-Rhino-Laryngol. 2015;272(2):357-62.

16. Vidigal TA, Haddad FLM, Gregório LC, Poyares D, Tufik S, Azeredo Bittencourt LR. Subjective, anatomical, and functional nasal evaluation of patients with obstructive sleep apnea syndrome. Sleep Breath. 2013;17(1):427-33.

17. Bertolazi AN, Fagondes SC, Hoff LS, Pedro D, Barreto SSM, Johns MW. Portuguese-language version of the Epworth sleepiness scale: validation for use in Brazil. J Bras Pneumol. 2009;35(9):877-83.

18. Arand D, Bonnet M, Hurwitz T, Mitler M, Rosa R, Sangal RB. The clinical use of the MSLT and MWT. Sleep. 2005;28(1):123-44.

19. Gomes AOC, Sampaio-Teixeira ACM, Trindade SHK, Trindade IEK. Áreas seccionais nasais de adultos sadios aferidas por rinometria acústica. Rev Bras Otorrinolaringol. 2008;74(5):746-59.

20. Trindade IEK, Conegliam PCP, Trindade SHK, Dias $\mathrm{NH}$, Sampaio-Teixeira ACLM. Internal nasal dimensions of adults with nasal obstruction. Braz J Otorhinolaryngol. 2013;79(5):575-81.

21. Nigro NCE, Nigro FAJ, Voegels RL, Mion O, Mello Junior JF. Rinometria acústica: correlação anatômica dos dois primeiros entalhes encontrados no rinograma. Braz J Otorhinolaryngol. 2005;71(2):149-54.

22. Pinto JA. Ronco e apnéia do sono. Rio de Janeiro: Revinter. 2000.

23. Chen X, Song J, Chen D, Sun J. Study of acoustic rhinometry and rhinomanometry for severe obstructive sleep apnea-hypopnea syndrome. $\mathrm{J}$ Clin Otorhinolaryngol Head Neck surg. 2011;25(17):780-2.

24. Morris LG, Setlur J, Burschtin OE, Steward $\mathrm{DL}$, Jacobs JB, Lee KC. Acoustic rhinometry predicts tolerance of nasal continuous positive airway pressure: a pilot study. Am J Rhinol. 2006;20(2):133-7.

25. Trindade IEK, Gomes AOC, Fernandes MLF, Trindade SHK, Silva Filho OG. Nasal airway dimensions of children with repaired unilateral cleft lip and palate. Cleft Palate Craniofac J. 2015;52(5):512-6.

26. Sin S, Wootton DM, McDonough JM, Nandalike K, Arens R. Anterior nasal resistance in obese children with obstructive sleep apnea syndrome (OSAS). Laryngoscope. 2014;124(11):2640-4.

27. Liu SA, Su MC, Jiang RS. Nasal patency measured by acoustic rhinometry in East Asian patients with sleep-disordered breathing. Am $\mathrm{J}$ Rhinol. 2006;20(3):274-7.

28. Şeneldir L, Koten M, Adali MK, Yağız R, Taş A, Karasalihoğlu AR. The evaluation of the outcomes of nasal obstruction surgery by acoustic rhinometry measurements and effects of nasal obstruction on daytime sleepiness. Ear Nose Throat J. 2012;22(1):12-20.

29. Bilston LE, Gandevia SC. Biomechanical properties of the human upper airway and their effect on its behavior during breathing and in obstructive sleep apnea. J Appl Physiol. 2013;116(3):314-24. 